Editorial

\title{
Ob-Gyn Gender Preferences of Gynecology Ambulatory Patients and Students' Choice of the Specialty
}

\section{Preferência de gênero de ginecologistas-obstetras entre pacientes de ambulatório de ginecologia e escolha da especialidade por estudantes}

\author{
Miriam da Silva Wanderley ${ }^{1}$ Dejano Tavares Sobral ${ }^{2}$ \\ ${ }^{1}$ Department of Gynecology and Obstetrics, Faculdade de Medicina, \\ Universidade de Brasília, Brasília, DF, Brazil \\ 2 Faculdade de Medicina, Universidade de Brasília, Brasília, DF, Brazil
}

Rev Bras Ginecol Obstet 2017;39:645-646.

In a systematic review and meta-analysis of 23 studies from different countries worldwide, Tobler et $\mathrm{al}^{1}$ reported that when choosing an Ob-Gyn physician, $8.3 \%$ of the patients investigated preferred a male physician, $50.2 \%$ reported a preference for a female physician, and $41.3 \%$ indicated no gender preference. Notably, the data from the United States sub analysis of studies showed a similar pattern $(53.2 \%$ of the patients preferred a female Ob-Gyn, and $38.5 \%$ admitted no gender preference). ${ }^{1}$

Individual studies have reported various rates for the patients' Ob-Gyn gender preferences, as well as for the factors or motives underlying the patients'responses. ${ }^{2-4}$ Moreover, gender restriction also occurs regarding student participation in Gynecology consultations, as other articles have mentioned. The bias regarding the involvement of the medical students seems multifaceted and could affect the students' perceptions of the specialty. ${ }^{5-9}$

Nevertheless, data from an exploratory study with Gynecology ambulatory patients conducted at a university hospital in the city of Brasilia, Brazil, and approved by the Committee of Ethics of the Faculty of Medicine of that institution (under CAAE 45773315.3.0000.5558) unveiled a distinct preference profile regarding Ob-Gyn. In the personal interview with 435 patients awaiting a call for their consultation, $2.1 \%$ among them preferred a male Ob-Gyn physician, $17.0 \%$ preferred a female one, and $80.9 \%$ indicated no gender preference. A contingency analysis showed a positive weak relationship of the patients' Ob-Gyn gender preferences with the frequency in which they attended Gynecology consultations (Kendal tau $\mathrm{b}=0.116$, $p=0.011, N=435$ ), but not with their educational level (Kendal tau $\mathrm{b}=0.70, p=0.116, N=435$ ). The cross-tabulation analysis also revealed a weak association between the

Address for correspondence Miriam da Silva Wanderley, Prof., MD, PhD, Faculdade de Medicina, Universidade de Brasília, Campus Universitário Darcy Ribeiro, 70210-900, Asa Norte, Brasília, DF, Brazil (e-mail: miriamsw@unb.br). patients' 3 generation categories (age) and the Ob-Gyn gender preference (Cramer V $=0.104, p=0.047, N=435$ ).

Among the middle generation patients (those aged between 35-54 years), $2.2 \%$ reported a preference for a male Ob-Gyn physician, $12.2 \%$ preferred a female one, and $85.6 \%$ had no gender preference. Both the younger generation (those aged between 12-34 years) and the older generation patients (those aged $\geq 55$ years) displayed a higher proportion (22.2\% and $22.5 \%$ respectively) of preference for a female Ob-Gyn physician and a lower percentage $(76.9 \%$ and $74.2 \%$ respectively) of reports of no gender preference. The similarities found between the younger and the older generations are a matter for future discussions.

Another contingency analysis revealed a congruence between the Ob-Gyn physician gender preferences and the patients' feelings about the prospect of the participation of a medical student in the Gynecology appointment: $0.2 \%$ of the patients stated they would only feel comfortable with male students, $10.6 \%$ reported that they would not feel comfortable with the participation of any student, $18.9 \%$ said they would only feel comfortable with female students, and $70.3 \%$ stated they would feel comfortable with either a female or a male student (70.3\%). A test showed a significant association between the two categories (comfort status and Ob-Gyn-gender): $63 \%$ of the patients had no gender preferences regarding the Ob-Gyn or the student, while $8.1 \%$ showed a preference for the female gender for both the Ob-Gyn physician and the student (Cramer V=0.265, $p<0.001, N=433$ ).

Could gender issues relate to the medical students' option for specialization in Ob-Gyn? In the past 23 years, we have observed no significant trends in the preference for the ObGyn specialization upon admission either among male or

Copyright $\odot 2017$ by Thieme Revinter Publicações Ltda, Rio de Janeiro, Brazil
DOI https://doi.org/ 10.1055/s-0037-1606840. ISSN 0100-7203.

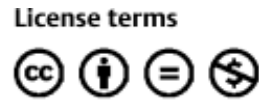


female students. Across that timeframe, the option for specialization in Ob-Gyn increased from admission (3.7\%) to graduation $(6.8 \%$ ) amidst 1,496 students, just as we had observed previously. ${ }^{10}$ However, we uncovered a definite downward trend in the choice of Ob-Gyn residency among male graduates (Chi-squared test for trend $=9.46, d f=1$, $p=0.002$ ), but not among female graduates (Chi-squared test for trend $=0.76, d f=1, p=0.38$ ).

Therefore, notwithstanding the Gynecology patients' presumed gender fairness, the choice of specialization in Ob-Gyn has turned out to be less attractive for male students along their undergraduate years. Some studies reported that a remarkable number of male students were denied participation in Ob-Gyn care, ${ }^{6}$ so they gained less experience and ability than female students, or that they indeed felt excluded from clinical subjects supposedly pertaining to females. ${ }^{7}$ Additionally, male medical students reported a significantly high proportion of discrimination against their gender by trainers (medical officers and specialists/consultants). ${ }^{9}$

Moreover, women may hold a negative stereotype about male Ob-Gyn physicians, depending on their expectations of desired gynecologic care. ${ }^{11}$ Such stereotype, in which male physicians are supposed to be unable to fully understand women's issues, and female physicians would be sympathetic because they share the same gender-related health conditions, could shape not only the patients' Ob-Gyn gender penchant but also generate a biased attitude toward male students, which could discourage them from pursuing the specialty.

Anyhow, we assume that doctors and teachers should be more sensitive to gender issues to minimize discriminatory attitudes and to make the training and eventual career choice of the medical students easier.

Conflicts of Interest

The authors have no conflicts of interest to disclose.

\section{References}

1 Tobler KJ, Wu J, Khafagy AM, Pier BD, Torrealday S, Vondra L. Gender preference of the obstetrician-gynecologist provider: a systematic review and meta-analysis. Obstet Gynecol 2016; 127:43S. Doi: 10.1097/01.AOG.0000483829.97196.8f

2 Makam A, Mallappa Saroja CS, Edwards G. Do women seeking care from obstetrician-gynaecologists prefer to see a female or a male doctor? Arch Gynecol Obstet 2010;281(03):443-447. Doi: 10.1007/s00404-009-1199-5

3 Amir H, Tibi Y, Groutz A, Amit A, Azem F. Unpredicted gender preference of obstetricians and gynecologists by Muslim IsraeliArab women. Patient Educ Couns 2012;86(02):259-263. Doi: 10.1016/j.pec.2011.05.016

4 Janssen SM, Lagro-Janssen AL. Physician's gender, communication style, patient preferences and patient satisfaction in gynecology and obstetrics: a systematic review. Patient Educ Couns 2012;89 (02):221-226. Doi: 10.1016/j.pec.2012.06.034

5 Mavis B, Vasilenko P, Schnuth R, Marshall J, Jeffs MC. Medical students' involvement in outpatient clinical encounters: a survey of patients and their obstetricians-gynecologists. Acad Med 2006; 81(03):290-296

6 Chang JC, Odrobina MR, McIntyre-Seltman K. The effect of student gender on the obstetrics and gynecology clerkship experience. J Womens Health (Larchmt) 2010;19(01):87-92. Doi: 10.1089/ jwh.2009.1357

7 Jiang X, Altomare C, Egan JF, Tocco DB, Schnatz PF. The ObGyn clerkship: are students denied the opportunity to provide patient care and what is the role of gender? Conn Med 2012;76(04):231-236

8 Yang J, Black K. Medical students in gynaecology clinics. Clin Teach 2014;11(04):254-258. Doi: 10.1111/tct.12122

9 Zahid AZ, Ismail Z, Abdullah B, Daud S. Gender bias in training of medical students in obstetrics and gynaecology: a myth or reality? Eur J Obstet Gynecol Reprod Biol 2015;186:17-21. Doi: 10.1016/j.ejogrb.2014.12.018

10 Wanderley MdaS, Sobral DT. [Choice of specialization in ob gyn]. Rev Bras Ginecol Obstet 2010;32(01):55-56. Doi: 10.1590/S010072032010000100009

11 Buck KS, Littleton HL. Stereotyped beliefs about male and female OB-GYNS: relationship to provider choice and patient satisfaction. J Psychosom Obstet Gynaecol 2014;35(01):1-7. Doi: 10.3109/ 0167482X.2013.866646 